\title{
Effect of Chronic Amiodarone Therapy on Defibrillation Energy Requirements in Humans
}

\author{
FRANK PELOSI, JR., M.D., HAKAN ORAL, M.D., MICHAEL H. KIM, M.D., \\ CHRISTIAN STICHERLING, M.D., LAURA HORWOOD, R.N., \\ BRADLEY P. KNIGHT, M.D., GREGORY F. MICHAUD, M.D., \\ FRED MORADY, M.D., and S. ADAM STRICKBERGER, M.D.
}

From the Division of Cardiology, Department of Internal Medicine, University of Michigan Health System, Ann Arbor, Michigan

\begin{abstract}
Amiodarone Effect on Defibrillation Energy Requirement. Introduction: The effect of oral amiodarone therapy on defibrillation energy requirements in patients with an implantable defibrillator has not been established.

Methods and Results: Twenty-one consecutive patients with implantable biphasic waveform defibrillators underwent a step-down determination of the defibrillation energy requirement $211 \pm$ 12 days before and $73 \pm 22$ days after initiation of amiodarone therapy (mean total dose $26.7 \pm$ $11.1 \mathrm{~g})$. Serum amiodarone and desethylamiodarone concentrations were measured at the time of defibrillation energy requirement determination. The mean defibrillation energy requirement before amiodarone therapy was $9.9 \pm 4.6 \mathrm{~J}$. After initiation of amiodarone therapy, the mean defibrillation energy requirement increased to $13.7 \pm 5.6 \mathrm{~J}(\mathrm{P}=\mathbf{0 . 0 0 4})$. A linear relationship between the amiodarone ( $\mathrm{P}=0.02, \mathrm{r}=0.6)$, desethylamiodarone $(\mathrm{P}=0.02, \mathrm{r}=0.6)$, and combined amiodaronedesethylamiodarone concentrations $(P=0.01, r=0.6)$ and the defibrillation energy requirement was noted. Stepwise regression analysis demonstrated that the combined amiodarone-desethylamiodarone concentration was the only independent predictor of increase in the defibrillation energy requirement.

Conclusion: Chronic oral amiodarone therapy increases the defibrillation energy requirement by approximately $62 \%$ in patients with an implantable defibrillator. The combined amiodaronedesethylamiodarone concentration is directly related to the increase in the defibrillation energy requirement. (J Cardiovasc Electrophysiol, Vol. 11, pp. 736-740, July 2000)
\end{abstract}

implantable defibrillator, ventricular fibrillation, defibrillation threshold

\section{Introduction}

Amiodarone is commonly prescribed for patients with an implantable defibrillator who receive frequent shocks for atrial or ventricular arrhythmias. ${ }^{1-4}$ The effect of amiodarone on the defibrillation energy requirement is unclear. Indirect evidence suggests that amiodarone elevates monophasic defibrillation energy requirements. . $^{5-8}$ However, a prospective comparison of defibrillation energy requirements before and after chronic amiodarone administration in patients with an implantable defibrillator has not been reported. The purpose of this study was to determine prospectively the effect of chronic amioda-

Address for correspondence: Frank Pelosi, Jr., M.D., University of Michigan Health System, 1500 East Medical Center Drive, B1F245, Ann Arbor, MI 48109-0022. Fax: 734-936-7026; E-mail: fpelosi @umich.edu

Manuscript received 13 December 1999; Accepted for publication 28 March 2000. rone therapy on the defibrillation energy requirement in patients with an implantable defibrillator.

\section{Methods}

\section{Patient Population}

The study population consisted of 21 patients ( 19 men and 2 women, mean age $64 \pm 15$ years) with an implantable defibrillator having biphasic waveforms who were treated with amiodarone (Table 1). Mean left ventricular ejection fraction was $0.31 \pm 0.13$. Coronary artery disease was present in 13 patients, nonischemic cardiomyopathy was present in 7 patients, and 1 patient had no structural heart disease. The indication for implantable defibrillator placement was aborted sudden cardiac death in 8 patients, sustained ventricular tachycardia in 6 , syncope in 4, and nonsustained ventricular tachycardia in 3. The indication for amiodarone therapy was atrial fibrillation in 13 patients and frequent symptomatic ventric- 
TABLE 1

Patient Characteristics

\begin{tabular}{|c|c|c|c|c|c|c|c|c|c|c|}
\hline Pt. No. & $\begin{array}{c}\text { Age } \\
\text { (years) }\end{array}$ & $\begin{array}{l}\text { Gender } \\
(\mathbf{M} / \mathbf{F})\end{array}$ & $\begin{array}{l}\text { Heart } \\
\text { Disease }\end{array}$ & $\begin{array}{l}\text { Ejection } \\
\text { Fraction }\end{array}$ & $\begin{array}{c}\text { ICD } \\
\text { Indication }\end{array}$ & $\begin{array}{l}\text { Active } \\
\text { Can }\end{array}$ & $\begin{array}{l}\text { Baseline } \\
\text { DER (J) }\end{array}$ & $\begin{array}{l}\text { Amiodarone } \\
\text { Indication }\end{array}$ & $\begin{array}{l}\text { Daily Dose } \\
\text { (mg/day) }\end{array}$ & $\begin{array}{c}\text { Duration of } \\
\text { Amiodarone } \\
\text { Therapy (days) }\end{array}$ \\
\hline 1 & 51 & $M$ & CAD & 0.33 & VT & 0 & 5 & $\overline{\mathrm{AF}}$ & 200 & 83 \\
\hline 2 & 66 & M & CAD & 0.27 & NSVT & 0 & 14 & $\mathrm{AF}$ & 200 & 97 \\
\hline 3 & 67 & M & CAD & 0.24 & SCD & 0 & 10 & $\mathrm{AF}$ & 200 & 24 \\
\hline 4 & 45 & M & NICM & 0.20 & VT & + & 10 & $\mathrm{AF}$ & 200 & 72 \\
\hline 5 & 58 & M & NICM & 0.18 & Syncope & 0 & 8 & $\mathrm{AF}$ & 200 & - \\
\hline 6 & 67 & M & CAD & 0.32 & SCD & 0 & 5 & $\mathrm{AF}$ & 200 & 68 \\
\hline 7 & 54 & M & NICM & 0.30 & SCD & 0 & 15 & $\mathrm{AF}$ & 400 & 52 \\
\hline 8 & 52 & M & CAD & 0.21 & VT & + & 8 & $\mathrm{AF}$ & 200 & 43 \\
\hline 9 & 25 & M & None & 0.60 & SCD & 0 & 15 & VT & 400 & 89 \\
\hline 10 & 70 & M & CAD & 0.20 & VT & + & 6 & VT & 400 & 78 \\
\hline 11 & 75 & M & CAD & - & NSVT & + & 6 & $\mathrm{AF}$ & 200 & 89 \\
\hline 12 & 46 & M & NICM & 0.30 & NSVT & + & 15 & VT & 400 & 85 \\
\hline 13 & 74 & M & $\mathrm{CAD}$ & 0.35 & VT & 0 & 6 & VT & 400 & 70 \\
\hline 14 & 47 & M & NICM & 0.25 & VT & + & 15 & $\mathrm{AF}$ & 200 & 57 \\
\hline 15 & 78 & $\mathrm{~F}$ & NICM & 0.35 & Syncope & + & 4 & VT & 400 & - \\
\hline 16 & 83 & $\mathrm{~F}$ & CAD & 0.25 & SCD & + & 11 & VT & 400 & - \\
\hline 17 & 71 & M & NICM & 0.20 & SCD & + & 15 & $\mathrm{AF}$ & 200 & 61 \\
\hline 18 & 84 & M & $\mathrm{CAD}$ & 0.41 & Syncope & + & 6 & VT & 400 & 91 \\
\hline 19 & 82 & M & CAD & 0.25 & Syncope & + & 12 & $\mathrm{AF}$ & 200 & 112 \\
\hline 20 & 70 & M & CAD & 0.60 & SCD & + & 5 & $\mathrm{AF}$ & 200 & 78 \\
\hline 21 & 78 & M & CAD & 0.55 & SCD & + & 7 & VT & 400 & 74 \\
\hline
\end{tabular}

$\overline{\mathrm{AF}}=$ atrial fibrillation; $\mathrm{CAD}=$ coronary artery disease; $\mathrm{DER}=$ defibrillation energy requirement; $\mathrm{F}=$ female; $\mathrm{ICD}=$ implantable cardioverter defibrillator; $\mathrm{M}=$ male; $\mathrm{NICM}=$ nonischemic cardiomyopathy; NSVT = nonsustained ventricular tachycardia; $\mathrm{SCD}=$ sudden cardiac death; VT $=$ ventricular tachycardia $;+=$ present; $0=$ absent; $-=$ unavailable.

ular arrhythmias in 8 . Nineteen patients had a defibrillator manufactured by Cardiac Pacemakers, Inc. (St. Paul, MN, USA) and 1 patient each had a defibrillator manufactured by Medtronic (Minneapolis, MN, USA) and by Intermedics (Angelton, TX, USA). A transvenous lead with 1 ( $\mathrm{n}=2$; Medtronic, Intermedics) or $2(\mathrm{n}=18$; Cardiac Pacemakers, Inc.) defibrillator coils was used in 20 patients. Epicardial defibrillation and sensing leads were used in the remaining patient. Total time from arrhythmia detection to delivery of shock was $9.5 \pm 3.0$ seconds. The charging time of the defibrillator after detection was $5.2 \pm 2.8$ seconds. The generator functioned as a defibrillation electrode in 13 patients. Among the 20 patients with a transvenous lead, 1 required a subcutaneous patch and 1 patient required a single epicardial defibrillation lead.

\section{Defibrillation Energy Requirement Determinations}

In the study patients, the defibrillation energy requirement was determined during the implantation procedure, 1 to 2 days after implant, 2 months later, and 2 months after amiodarone therapy was initiated. The most recently determined defibrillation energy requirement before the initiation of amiodarone was defined as the baseline defibrillation energy requirement. The mean time between defibrillator implantation and baseline defibrillation energy requirement determination was $409 \pm$ 450 days. The mean time interval between the baseline defibrillation energy requirement and initiation of amiodarone therapy was $211 \pm 212$ days.

At each defibrillation energy requirement determina- tion, a step-down protocol was used $(15,10,8,6,4,3,2$, and $1 \mathrm{~J}$ ). After ventricular fibrillation was induced using $60-\mathrm{Hz}$ pacing, the implantable defibrillator sensed, charged, and delivered the defibrillation shock. If normal rhythm was restored with the first shock, then the stepdown protocol was continued until the first shock was ineffective. When the first shock failed during implantation testing, the programmed shock energy for the next ventricular fibrillation induction was $20 \mathrm{~J}$. If the 20-J shock failed, then a subcutaneous defibrillation electrode was added to the system, and the step-down protocol was repeated. At least 5 minutes elapsed between each ventricular fibrillation induction.

\section{Amiodarone Administration}

The mean total dose of amiodarone before the amiodarone defibrillation energy requirement determination was $26.7 \pm 11.1 \mathrm{~g}$. The mean total dose of amiodarone consisted of a mean amiodarone loading dose of $680 \pm$ $166 \mathrm{mg} /$ day for $12.6 \pm 5.9$ days, and a total mean loading dose of $9.1 \pm 5.2 \mathrm{~g}$. This was followed by a maintenance dose of amiodarone $276 \pm 100 \mathrm{mg} /$ day. The total duration of amiodarone therapy before the amiodarone defibrillation energy requirement determination was $73 \pm 21$ days.

At the time of defibrillation energy requirement determination 2 months after the initiation of amiodarone therapy, a venous blood sample was obtained and the serum amiodarone and desethylamiodarone concentrations determined using high-performance liquid chromatography. 


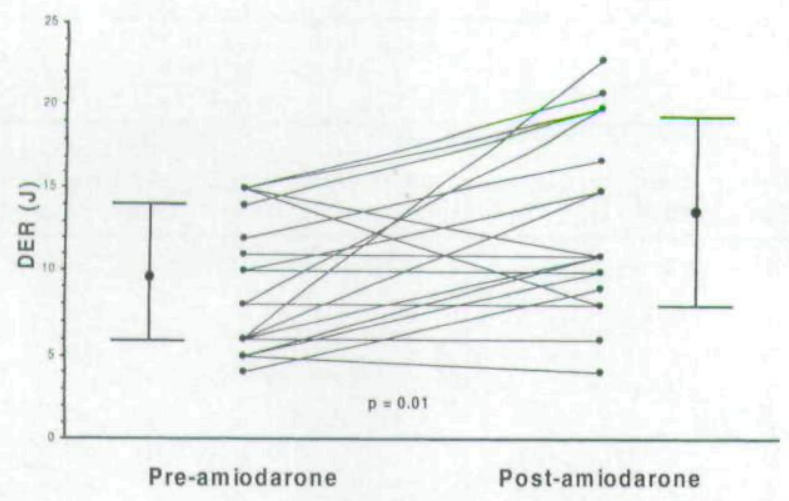

Figure 1. Comparison of individual defibrillation energy requirements (DER) before and after chronic oral amiodarone therapy.

\section{Statistical Analysis}

Continuous variables are expressed as mean \pm 1 SD and were compared using a paired or unpaired $t$-test, as appropriate. Regression analysis was used to assess a relationship between two continuous variables. Stepwise regression analysis was used to test for independence between variables. A Chi-square or Fisher's exact test was used to compare nominal variables. $\mathrm{P}<0.05$ was considered statistically significant.

\section{Results}

The baseline defibrillation energy requirement was $9.4 \pm 4.6 \mathrm{~J}$ and the defibrillation energy requirement after amiodarone therapy was $13.7 \pm 5.6 \mathrm{~J}(\mathrm{P}=0.01$; Fig. 1). The defibrillation energy requirement increased by $4.0 \pm 5.3 \mathrm{~J}$ or $62 \% \pm 74 \%$. The shocking resistance before $(47 \pm 12 \Omega)$ and after amiodarone therapy ( $46 \pm$ $7 \Omega$ ) did not change significantly $(\mathrm{P}=0.8)$.

The mean amiodarone, desethylamiodarone, and combined amiodarone-desethylamiodarone concentrations were $1.1 \pm 0.56 \mathrm{mg} / \mathrm{dL}, 1.0 \pm 0.44 \mathrm{mg} / \mathrm{dL}$, and $2.1 \pm$ $0.96 \mathrm{mg} / \mathrm{dL}$, respectively. There was a linear relationship between the serum amiodarone concentration and the defibrillation energy requirement $(r=0.6, P=0.02)$, the change in defibrillation energy requirement $(\mathrm{r}=0.8, \mathrm{P}=$ $0.001)$, and the percent change in defibrillation energy requirement $(r=0.7, P=0.004$; Fig. 2$)$. The serum desethylamiodarone concentration also demonstrated a linear relationship with the defibrillation energy requirement $(r=0.6, P=0.02)$, change in the defibrillation energy requirement $(\mathrm{r}=0.8, \mathrm{P}=0.002)$, and percent change in the defibrillation energy requirement $(r=0.7$, $\mathrm{P}=0.003$; Fig. 3). Additionally, a linear relationship was observed between the combined amiodarone-desethylamiodarone concentrations and the defibrillation energy requirement $(r=0.6, P=0.01)$, change in the defibrillation energy requirement $(r=0.7, P=0.002)$, and percent change in defibrillation energy requirement $(r=0.7, P=0.002$; Fig. 4). Stepwise regression analysis of amiodarone, desethylamiodarone, and combined amiodarone-desethylamiodarone concentrations demon- strated that only the combined concentrations of amiodarone and desethylamiodarone were independently associated with the defibrillation energy requirement.

There was no relationship between the defibrillation energy requirement and the daily amiodarone dose $(\mathrm{P}=$ $0.6)$, duration of amiodarone therapy $(\mathrm{P}=0.2)$, total dose of amiodarone $(\mathrm{P}=0.1)$, or interval between the defibrillation energy requirement determinations $(\mathrm{P}=$ $0.4)$. No clinical characteristics, including age, gender, ejection fraction, type of heart disease, or indication for implantable defibrillator therapy, correlated with the defibrillation energy requirement, change in defibrillation energy requirement, or percent change in the defibrillation energy requirement.

\section{Discussion}

\section{Major Findings}

The results of this prospective study demonstrate that chronic amiodarone therapy increases the defibrillation energy requirement by approximately $60 \%$. Furthermore, the combined serum concentrations of amiodarone and desethylamiodarone independently correlate with the defibrillation energy requirement after initiation of amio-
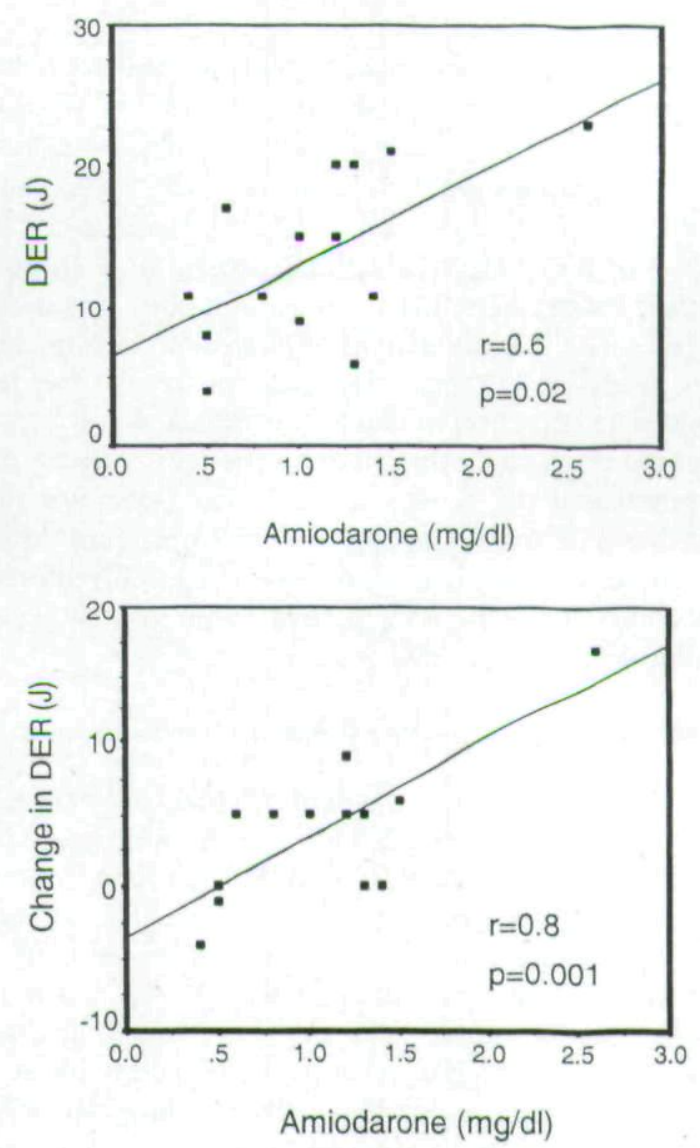

Figure 2. Correlation of serum amiodarone concentrations with defibrillation energy requirement (DER; top panel) and change in defibrillation energy requirement (bottom panel). 

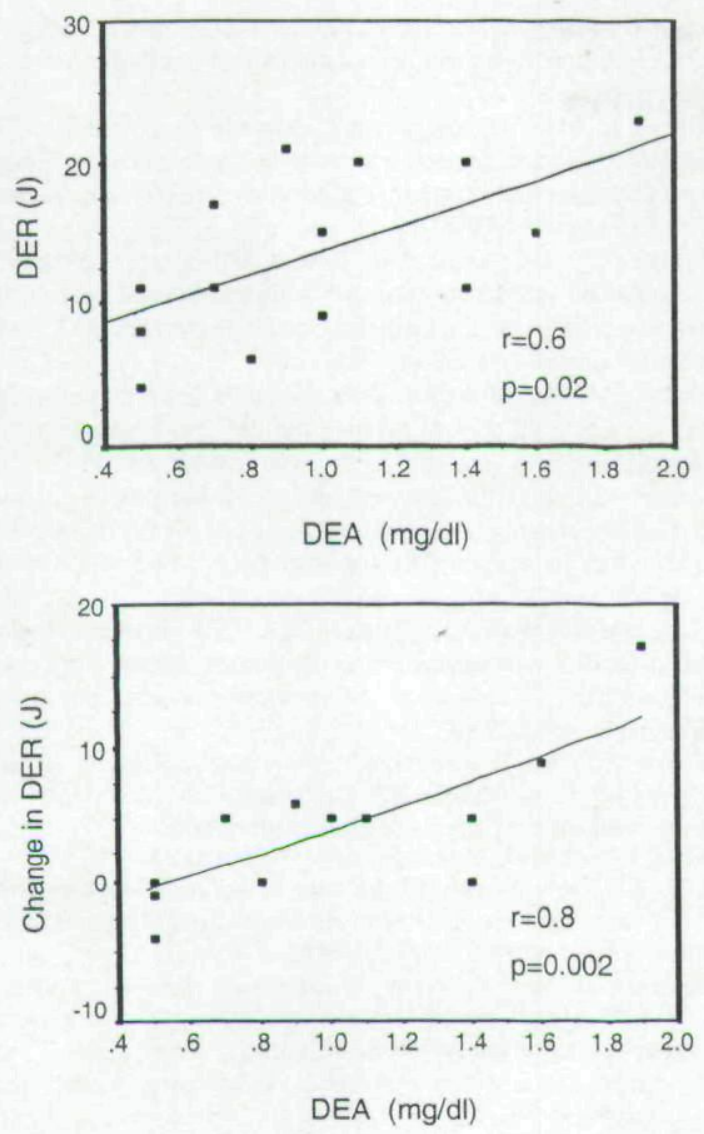

Figure 3. Correlation of serum desethylamiodarone (DEA) concentration with defibrillation energy requirement (DER; top panel) and change in defibrillation energy requirement (bottom panel).

darone therapy in patients with an implantable defibrillator.

\section{Mechanism}

The mechanism of amiodarone's effects on the defibrillation energy requirement is unclear, perhaps because the mechanism of successful defibrillation is controversial. Some investigators proposed that a defibrillation shock must be of sufficient energy to depolarize the myocardium in varying states of refractoriness. ${ }^{9}$ This results in uniform ventricular refractoriness and termination of the fibrillation. Amiodarone and its metabolite desethylamiodarone increase action potential duration by blocking potassium channels. ${ }^{10,11}$ Amiodarone's Class III effects may increase the volume of refractory myocardium, thereby necessitating a stronger shock for successful defibrillation.

\section{Previous Studies}

This is the first published study to compare the defibrillation energy requirement before and after the initiation of oral amiodarone therapy. The present study evaluated this relationship only with biphasic defibrillation.
This is also the first published study to demonstrate that the amiodarone and desethylamiodarone concentrations correlate with the biphasic defibrillation energy requirement.

Only one previous study evaluated the relationship between amiodarone and desethylamiodarone concentrations and the defibrillation energy requirement. ${ }^{8}$ In that study, amiodarone therapy correlated with an increased monophasic defibrillation energy requirement and a higher frequency of a subcutaneous defibrillation electrode use. ${ }^{8}$ However, the drug concentration did not correlate with defibrillation efficacy. ${ }^{8}$ The difference between that previous study and the present study may be due to different effects of amiodarone on biphasic and monophasic defibrillation.

\section{Limitations}

The major limitation of this study is the small sample size. Second, this study did not control for the effect of time on the defibrillation energy requirement. The mean time from defibrillator implantation to the study's baseline defibrillation requirement determination was 400 days. If biphasic defibrillation efficacy changes over time, it occurs within 2 months of implantation and then probably remains stable over at least 2 years. ${ }^{12-14}$
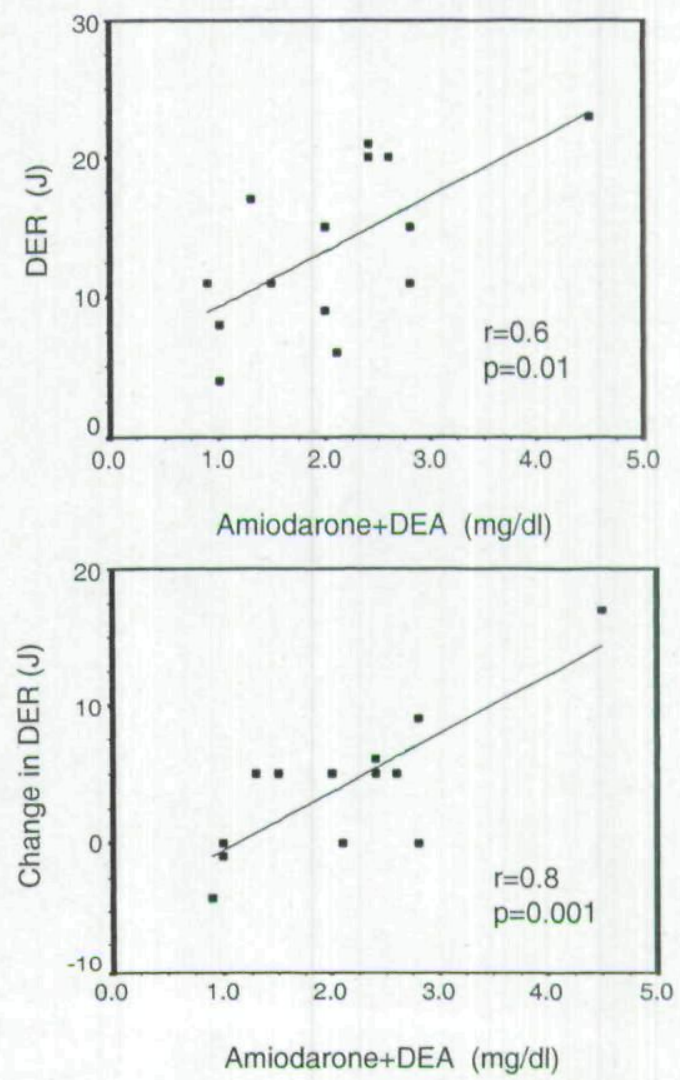

Figure 4. Correlation of combined serum concentration of amiodarone and desethylamiodarone (amiodarone $+D E A$ ) with defibrillation energy requirement (DER; top panel) and change in defibrillation energy requirement (bottom panel). 


\section{Clinical Implications}

The results of this study suggest that the defibrillation energy requirement should be determined 2 to 3 months after amiodarone therapy is initiated in patients with an implantable defibrillator. This may be especially important for patients in whom increases in the defibrillation energy requirement may compromise the defibrillator safety margin.

\section{References}

1. Gosselink ATM, Crijns HJGM, van Gelder IC, Hillige H, Wiesfeld WC, Lie KI: Efficacy and safety of low dose amiodarone for the long term maintenance of sinus rhythm after electrical cardioversion of refractory atrial fibrillation or flutter. JAMA 1992;267: 3289-3293.

2. Nademanee K, Singh BN, Hendrickson J, Intarachot V, Lopez B, Feld G, Cannom DS, Weiss JL: Amiodarone in refractory life threatening ventricular arrhythmias. Ann Intern Med 1983;98:577584.

3. Herre JM, Sauve MJ, Malme P, Griffin JC, Helmy I, Langberg JJ, Goldberg H, Scheinman MM: Long-term results of amiodarone therapy in patients with recurrent sustained ventricular tachycardia or ventricular fibrillation. J Am Coll Cardiol 1989;13:442-449.

4. Tieleman RG, Gosselink ATM, Crijns HJGM, van Gelder IC, van den Berg MP, de Kam PJ, van Gilst WH, Lie KI: Efficacy, safety and determinants of conversion of atrial fibrillation and flutter with oral amiodarone. Am J Cardiol 1997;79:53-57.

5. Huang SKS, Tan de Guzman WL, Chenarides JG, Okike NO, Vander Salm TJ: Effects of long-term amiodarone therapy on the defibrillation threshold and the rate of shocks of implantable defibrillators. Am Heart J 1991;12:720-727.
6. Jung W, Manz M, Pizzulli L, Pfeiffer D, Lüderitz B: Effects of chronic amiodarone therapy on defibrillation threshold. Am J Cardiol 1992;70:1023-1027.

7. Daoud E, Man KC, Horwood L, Morady F, Strickberger SA: Relation between amiodarone and desethylamiodarone plasma concentrations and ventricular defibrillation energy requirements. Am J Cardiol 1997;79:97-100.

8. Behrens S, Li C, Franz MR: Effects of long-term amiodarone treatment on ventricular fibrillation vulnerability and defibrillation efficacy in response to monophasic and biphasic shocks. J Cardiovasc Pharmacol 1997;30:412-418.

9. Dillon SM: Optical recordings in the rabbit heart show that defibrillation strength shocks prolong the duration of depolarization and the refractory period. Circ Res 1991;69:842-856.

10. Balser JR, Bennet PB, Hondeghem LM, Roden DM: Suppression of time-dependent outward current in guinea pig ventricular myocytes: Actions of quinidine and amiodarone. Circ Res 1991;69: 519-529.

11. Anderson KP, Walker R, Dustman T, Lux RL, Ershler PR, Kates RE, Urie PM: Rate-related electrophysiologic effects of long-term administration of amiodarone on ventricular myocardium in vivo. Circulation 1989;79:948-958.

12. Tokano T, Pelosi F, Flemming M, Horwood L, Sousa JJ, Zivin A, Knight BP, Goyal R, Man KC, Strickberger SA, Morady F: Longterm evaluation of the ventricular defibrillation energy requirement. J Cardiovasc Electrophysiol 1998;9:820-824.

13. Martin D, Roy J, Venditti J: Increase in defibrillation threshold in non-thoracotomy implantable defibrillators using a biphasic waveform. Am J Cardiol 1995;76:263-266.

14. Newman D, Barr A, Greene M, Martin D, Ham M, Thorne S, Dorian P: A population-based method for the estimation of defibrillation energy requirements in humans: Assessment of timedependent effects with a transvenous defibrillation system. Circulation 1997;96:267-273. 
This document is a scanned copy of a printed document. No warranty is given about the accuracy of the copy. Users should refer to the original published version of the material. 